\title{
Article \\ Specific Physical Ability Prediction in Youth Basketball Players According to Playing Position
}

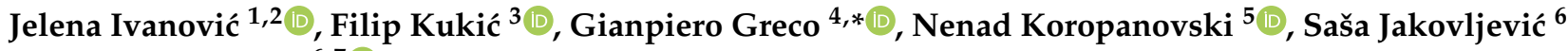 \\ and Milivoj Dopsaj ${ }^{6,7}$
}

check for

updates

Citation: Ivanović, J.; Kukić, F.;

Greco, G.; Koropanovski, N.; Jakovljević, S.; Dopsaj, M. Specific Physical Ability Prediction in Youth Basketball Players According to Playing Position. Int. J. Environ. Res. Public Health 2022, 19, 977. https:// doi.org/10.3390/ijerph19020977

Academic Editor: Richard B. Kreider

Received: 14 December 2021

Accepted: 13 January 2022

Published: 16 January 2022

Publisher's Note: MDPI stays neutral with regard to jurisdictional claims in published maps and institutional affiliations.

Copyright: (C) 2022 by the authors Licensee MDPI, Basel, Switzerland. This article is an open access article distributed under the terms and conditions of the Creative Commons Attribution (CC BY) license (https:// creativecommons.org/licenses/by/ $4.0 /)$.
1 Serbian Institute for Sport and Sports Medicine, 72 Kneza Višeslava Street, 11030 Belgrade, Serbia; jelena.ivanovic@rzsport.gov.rs

2 Faculty of Sport, University “Union-Nikola Tesla”, Narodnih Heroja 30/I, 11070 Belgrade, Serbia

3 Police Sports Education Center, Abu Dhabi Police, Abu Dhabi 253, United Arab Emirates; filip.kukic@gmail.com

4 Department of Basic Medical Sciences, Neuroscience and Sense Organs, University of Study of Bari, 70121 Bari, Italy

5 Department of Criminalistics, University of Criminal Investigation and Police Studies, 11080 Belgrade, Serbia; nenad.koropanovski@kpu.edu.rs

6 Faculty for Sport and Physical Education, Belgrade University, 11000 Belgrade, Serbia; sasa.jakovljevic@fsfv.bg.ac.rs (S.J.); milivoj.dopsaj@gmail.com (M.D.)

7 Institute of Sport, Tourism and Service, South Ural State University, 454080 Chelyabinsk, Russia

* Correspondence: gianpierogreco.phd@yahoo.com

\begin{abstract}
This study investigated the hierarchical structure of physical characteristics in elite young (i.e., U17-U19) basketball players according to playing positions. In addition, their predictive value of physical characteristics was determined for the evaluation of players' physical preparedness. Sixty elite male basketball players performed 13 standardized specific field tests in order to assess the explosive power of lower limbs, speed, and change-of-direction speed. They were divided into three groups according to playing positions (guard [ $n=28]$, forward [ $n=22]$, center $[n=10])$. The basic characteristics of the tested sample were: age $=17.36 \pm 1.04$ years, body height $=192.80 \pm 4.49 \mathrm{~cm}$, body mass $=79.83 \pm 6.94 \mathrm{~kg}$, and basketball experience $=9.38 \pm 2.10$ years for guards; age $=18.00 \pm 1.00$ years, body height $=201.48 \pm 3.14 \mathrm{~cm}$, body mass $=90.93 \pm 9.85 \mathrm{~kg}$, and basketball experience $=9.93 \pm 2.28$ years for forwards; and age $=17.60 \pm 1.43$ years; body height $=207.20 \pm 3.29 \mathrm{~cm}$, body mass $=104.00 \pm 9.64 \mathrm{~kg}$, and basketball experience $=9.20 \pm 1.62$ years for centers. For all playing positions factor analysis extracted three factors, which cumulatively explained $76.87,88.12$ and $87.63 \%$ of variance, respectively. The assessed performance measures were defined as significant $(p<0.001)$, with regression models of physical performance index (PP $\left.\mathrm{INDEX}_{\mathrm{N}}\right)$. $\mathrm{PP}_{\mathrm{INDEX}}$ of guards $=-6.860+(0.932 \times t$-test $)-(1.656 \times$ Acceleration $15 \mathrm{~m})-(0.020 \times$ Countermovement jump); PP INDEX of forwards $=-3.436-(0.046 \times$ Countermovement jump with arm swing $)-$ $(1.295 \times$ Acceleration $15 \mathrm{~m})+(0.582 \times$ Control of dribbling $) ; P_{\text {INDEX }}$ of centers $=-4.126+(0.604$ $\times$ Control of dribbling $)-(1.315 \times$ Acceleration $15 \mathrm{~m})-(0.037 \times$ Sargent jump $)$. A model for the evaluation of physical performance of young basketball players has been defined. In addition, this model could be used as a reference model for selection procedures, as well as to monitor the efficacy of applied training programmes within the short, medium and long-term periodization.
\end{abstract}

Keywords: measurement; power test; speed test; change of direction speed test; guard; forward; center

\section{Introduction}

Body height, muscular power, speed, and strength are all important elements of the basketball player profile. Power, speed, and change of direction speed significantly contribute to the movement efficiency of basketball players with the ball and without it, as well as in technical and tactical elements of basketball game [1-3]. While body height 
is genetically predetermined, power, speed and change of direction speed are subject to training adaptation and could be used for the assessment of players' physical potential to overcome the challenges of a basketball game [3-5]. This is important in selection as well as training evaluation processes. Identification of younger players who have good physical potentials for basketball game reduces the probability of false selection, while early detection of deficits in the main physical abilities indicates that the training could be adjusted and may reduce the risk of unwanted injuries.

Managing the selection and training process depends on the adequacy of the assessment system in collecting information on athlete's or a team's training level in order to provide a precise evaluation of training level [6-8]. Furthermore, the usability of results obtained by the assessment depends on the specificity and sensitivity of the applied tests. The more specific the test is with regard to sport, the representation of competitive readiness is more valid $[1,8,9]$. If the correct data is collected from athletes, the coach can follow the trend in core physical abilities of basketball players through the age categories, and he can timely correct the training program to attain the short, medium, and long-term goals.

The available bibliography reveals the lack of design and use of specific tests to assess the physical attributes of the young basketball players, especially according to age categories and playing positions $[1,8]$. Growth and maturation affect physical abilities and physical performance [10-12], while different basketball positions present different demands and require specific physical attributes [13-15]. According to the results of a previous systematic review [1], the least common evaluated capacities in basketball players in literature are speed and agility. Tests of a generic nature have more frequently been used for assessing physical fitness in basketball players, e.g., aerobic and anaerobic capacity or jump performance $[1,3,8,9,13-16]$. Besides, only a few pieces of research have dealt with specific tests while dribbling the ball in basketball $[1,8]$. Consequently, talent identification, selection, and evaluation of training processes are very important parts of the systematic approach to the consistent competitive success of basketball team.

Considering the aforementioned factors, this study aimed to determine the hierarchical structure of physical characteristics in elite young (i.e., U17-U19) basketball players according to playing positions. In addition, their predictive value of physical characteristics was determined for the evaluation of players' physical preparedness. It was, firstly, hypothesized that significant hierarchical structure of physical abilities will be determined. Secondly, it was hypothesized that the highest ranked variables from the hierarchical structure could be the best predictors of players' physical performance.

\section{Materials and Methods}

\subsection{Participants}

The sample consisted of 60 male basketball players from the U19 and U17 Serbian national team. In order to obtain the most informative indicators to improve the technological process of managing, we recruited relatively large samples of participants to secure a sufficient statistical power. Besides, we selected a group of elite basketball players who won eight international medals in a period of four years during the biggest World and European competitions. They were allocated into three groups according to playing positions, as follows: Guards ( $n=28$, i.e., point guard and shooting guard), forwards ( $n=22$, i.e., small forward and power forward) and centers $(n=10)$. Basic characteristics of the tested sample were: age $=17.36 \pm 1.04$ years, $18.00 \pm 1.00$ years, $17.60 \pm 1.43$ years; body height $=192.80 \pm 4.49 \mathrm{~cm}, 201.48 \pm 3.14 \mathrm{~cm}, 207.20 \pm 3.29 \mathrm{~cm}$; body mass $=79.83 \pm 6.94 \mathrm{~kg}, 90.93 \pm 9.85 \mathrm{~kg}, 104.00 \pm 9.64 \mathrm{~kg}$; and training experience $=9.38 \pm 2.10$ years, $9.93 \pm 2.28$ years, $9.20 \pm 1.62$ years for guards, forwards and centers, respectively. All participants (athletes, coaches, and parents) were informed that their data may be used anonymously for scientific purposes and they were informed about the potential risks and discomforts associated with the investigation, and measurements were conducted out with their parental consent in line with the Helsinki Declaration. The Institutional Ethics Committee approved the research. 


\subsection{Measurement Procedure}

All the tests were performed by the Serbian Institute of Sport and Sports Medicine at the beginning of the main pre-competitive mesocycle. Players were requested to refrain from strenuous exercise for at least $48 \mathrm{~h}$, and from eating $2 \mathrm{~h}$ before testing. The testing session was carried out during morning hours between 10:00 and 12:00 a.m.

Before tests, players had performed a standardised warm-up, consisting of 5 min jogging, 5 min dynamic stretching, and $5 \mathrm{~min}$ of short acceleration-decelerations, gradual building of running velocity, submaximal jumping, and agility exercises. For the last five minutes of warm-up, players performed tests with submaximal intensity to potentiate specific muscles and joints. It is of note that the Serbian Institute of Sport and Sports Medicine asses the best Serbian athletes (i.e., members of the national teams) on a regular basis so the used tests were familiar to athletes. The assessment protocol for basketball athletes consists of sprint tests (with and without the ball), change of direction speed tests (with and without the ball), and vertical jump tests. Straight run speed, change of direction speed, and vertical jump heights were measured using Infrared timing gates and contact mat (Fusion sport, SmartJump and SmartSpeed, Grabba International Pty Ltd., Australia). The time of the run dribble was measured in seconds, with an accuracy of $\pm 0.01 \mathrm{~s}$. Jump tests are characterized by a very good test-retest reliability (in general Intraclass correlation coefficients are higher than 0.90$)[13,16,17]$.

\subsubsection{Sprint Tests}

A $20 \mathrm{~m}$ sprint was performed from the standing position with the front foot placed on the line $30 \mathrm{~cm}$ behind the photocells. Times were recorded by infrared timing gates placed at the start, at $5 \mathrm{~m}$ (first-step quickness [Q5m]), $15 \mathrm{~m}$ (acceleration [A15m]), and finish line (Sprint $20 \mathrm{~m}$ [S20m]). Players performed the $20 \mathrm{~m}$ sprint two times without the ball and two times while dribbling the ball $\left(\mathrm{S} 20 \mathrm{~m}_{\mathrm{D}}\right)$. The best time obtained from the trial was used for statistical analysis $[8,13,18]$.

\subsubsection{Change of Direction Speed with and without the Ball}

The following five tests were used to assess change-of-direction speed: $t$-test $\left(\mathrm{T}_{\mathrm{TEST}}\right)$, Slalom, Control dribble test (COND), Defensive movements test (DM), Change of direction speed test $[2,3,8,16,18]$. For the purpose of this study, we applied the standardized procedures used in the previous study [8].

$\mathrm{T}_{\text {TEST }}$ requires the athlete to move in a T-shaped pattern. According to earlier described procedures $[8,13,16,18]$, the photocells were placed at the starting line and in line with central cone positioned $9 \mathrm{~m}$ away from starting position. The athletes started from the standing position, and ran forward $9 \mathrm{~m}$ as fast as possible. Then, they shuffled $4.5 \mathrm{~m}$ laterally to the left without crossing their feet to another cone. After touching this cone, they shuffled laterally $9 \mathrm{~m}$ to the right to a third cone, touched it, side shuffled back to the middle cone, and ran backward to where they started.

In case of Slalom (Slalom), and Slalom while dribbling the ball (Slalom $)$, each participant started the test with his feet behind the baseline of the basketball court. Subjects were required to run (dribble), as fast as possible up and down the course around the three cones placed linearly with $2.6 \mathrm{~m}$ distance. They performed two trials with and without the ball and the fasters ones were used for the analysis [8].

The COND test was performed at the $5.8 \mathrm{~m} \times 3.6 \mathrm{~m}$ rectangle polygon marked by six cones positioned as follows: two at both ends of the free-throw lane, two at the baseline aligned with those at the free-throw line, one in the middle of the rectangle, and one that marked the starting point [8]. The athletes were required to navigate dribbling through a course as fast as possible. The athletes started with their non-dominant hand on the non-dominant side of cone A. They dribbled with non-dominant hand to the non-dominant side of cone $\mathrm{B}$, and then proceed to cone $\mathrm{C}$ and cone $\mathrm{D}$, dribbling with the dominant hand. The course continued with the non-dominant hand to cone $\mathrm{E}$ and then with the dominant hand to cone F where the test was completed (Figure 1). Three trials were completed for the 
test. The first was a practice trial and the sum of the second (starting with non-dominant hand) and third trials (starting with dominant hand) was retained for analysis.
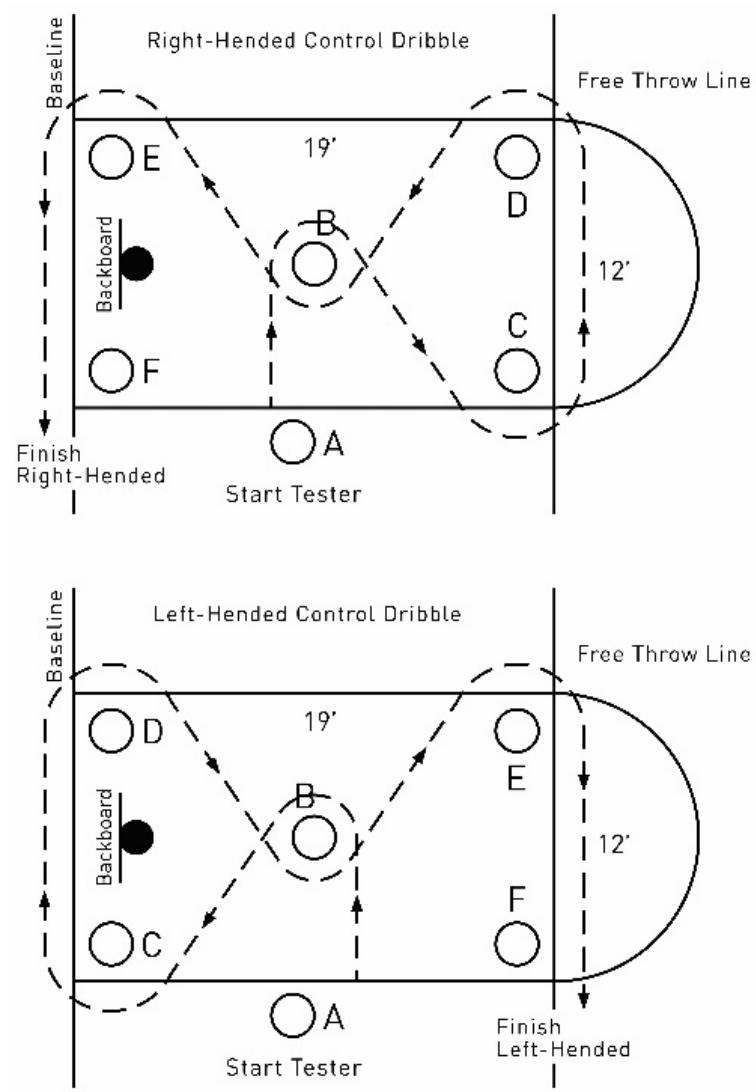

Figure 1. Schematic illustration of the Control of dribbling test. A, B, C, D, E, F-cones; dotted arrow-direction of dribbling.

The DM was used to evaluate the performance of defensive movements. It was performed at the same rectangle polygon as COND, but two cons were positioned at the halfway point of the longer edges of the rectangle. This test was carried following the procedure described in a previous study [8]. The player was required to shuffle laterally without crossing the feet in a sequence of seven changes of direction. Whenever the players changed direction, they were required to touch the floor and execute a drop-step (changing direction by moving the trailing foot in the sliding motion to the new direction (Figure 2). The fastest of the two trials was recorded for the analysis.

A change of direction test (COD) consists of a sprint with several changes of direction. The athletes started in the triple-threat position behind the baseline of the basketball court. Players were required to run (dribble) and to change direction as fast as possible to two different lines, namely, the near free-throw line $(5.8 \mathrm{~m})$ and the half-court line $(14 \mathrm{~m})$. The athletes sprinted to the free-throw line first and back to the baseline, then to the half-court line and back to the baseline, and finally to the free-throw line again and back to the baseline. Before every change of direction, they were required to step on the line with one foot. After changing direction, they were required to change the dribbling hand. Each athlete was allowed two trials with and without the ball and the fastest one was retained for analysis. Two players performed the test at the same time to encourage maximal effort [8]. 


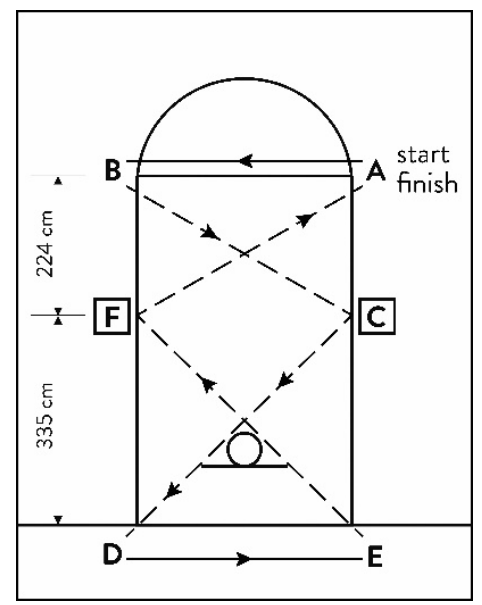

Figure 2. Schematic illustration of the Defensive movements test. A, B, C, D, E, F-cones; dotted arrow-direction of movements.

\subsubsection{Vertical Jumps}

The following four types of vertical jump were performed: Sargent jump (SGJ), Squat Jump (SJ), Countermovement jump with arm swing $\left(\mathrm{CMJ}_{\mathrm{AS}}\right)$ and Countermovement jump (CMJ). In case of SGJ, the athlete chalked the end of his/her fingertips, stood sideways onto the wall, kept both feet on the ground, reached up as high as possible with one hand and marked the wall with the tips of the fingers (M1). From a static position, they jumped as high as possible and marked the wall with the chalk on their fingers (M2). The distance between M1 and M2 was used to calculate jump height. The athlete repeated the test 2 times [2]. SJ and CMJ vertical jump height were performed according to well-established procedures [13,16-18]. In short, SJ was performed from the 90-degree semi-squat position using only the maximal contraction of lower limbs, while CMJ was performed utilizing the energy from the stretch-shortening cycle. In SJ and CMJ, hands were kept at the hips for the entire movement to eliminate any influence of the arm. A CMJ $\mathrm{AS}_{\mathrm{S}}$ was performed the same way as CMJ but players were allowed to swing with their hands upward. Two maximal jumps were performed, and the highest result was registered as the final result.

\subsection{Statistical Procedures}

The mean and standard deviation values for each test were calculated for each subgroup (guards, forwards, and centers). For all the tests involving several trials, test-retest reliability was assessed using intraclass correlation coefficients (ICC). For defining the structure, i.e., real qualitative relationships between variables, the principal component analysis (PCA) was used. A multivariate assessment of the adequacy of the raw data was carried out using the Kaiser-Meyer-Olkin (KMO) measure of sampling adequacy and Bartlett's Tests of sphericity $(p<0.001)$, for which statistical significance was expressed in terms of a chi-square $\left(\chi^{2}\right)$. Eigenvalues $>1$ were considered for the extraction of principal components. A Direct Oblimin rotation method was performed in order to identify the high correlation of components and guarantee that each principal component offered different information [19]. A criterion variable from factor analysis was used as a representation of the player's multidimensional physical performance index $\left(\mathrm{PP}_{\mathrm{INDEX}}\right)$ according to playing position so each player could be compared against the criterion value for their playing position [20]. Multiple regression analysis with the $\mathrm{PP}_{\mathrm{INDEX}}$ as the criterion variable and the performance test variables as predictor variables determined the unique evaluation of specific preparedness of basketball players according to playing position [20]. Statistical significance for all analyses was defined as $p<0.001$. All statistical operations were carried out by applying the Microsoft ${ }^{\circledR}$ Office Excel 2010 and the SPSS for Windows, Release 20.0 (Copyright () SPSS Inc., Chicago, IL, USA, 1989-2002). 


\section{Results}

Results for the descriptive statistics (Mean and Standard deviation) of the observed characteristics with regard to different playing position and Intraclass correlation coefficients (ICCs) for relative test-retest reliability are shown in Table 1. It can be observed that, in terms of positions, forwards were faster than guards and centers in Q5m and Q5 $\mathrm{m}_{\mathrm{D}}$, while guards were faster than forwards and centers in the majority of change-of-direction speed and sprint tests. In addition, guards achieved a greater jump height compared with forwards and centers. The average inter-item correlation in all variables described mutual correlation within a correlation matrix at a statistically significant level at $p<0.001$ (Bartlett's test of Sphericity) and ranged between 0.689 for $\mathrm{A} 15 \mathrm{~m}_{\mathrm{D}}$ and 0.992 for CMJ, indicating a good reliability.

Table 1. Descriptive statistics and Intraclass correlation coefficients.

\begin{tabular}{|c|c|c|c|c|c|}
\hline & \multirow{2}{*}{$\begin{array}{c}\text { Guard } \\
\text { Mean } \pm \text { SD }\end{array}$} & \multirow{2}{*}{$\begin{array}{c}\text { Forward } \\
\text { Mean } \pm \text { SD }\end{array}$} & \multirow{2}{*}{$\begin{array}{c}\text { Center } \\
\text { Mean } \pm \text { SD }\end{array}$} & \multicolumn{2}{|c|}{ Test-Retest Reliability } \\
\hline & & & & $\begin{array}{c}\text { Average } \\
\text { Int-Item } \\
\text { Correlation }\end{array}$ & $\begin{array}{c}\text { Bartlett's } \\
\text { Test of } \\
\text { Sphericity }\end{array}$ \\
\hline Q5m (s) & $1.817 \pm 0.413$ & $1.606 \pm 0.522$ & $1.820 \pm 0.547$ & 0.977 & $\mathrm{~F}=42.775 *$ \\
\hline Q5m $\mathrm{D}(\mathrm{s})$ & $1.883 \pm 0.426$ & $1.721 \pm 0.647$ & $1.905 \pm 0.587$ & 0.732 & $\mathrm{~F}=3.735 *$ \\
\hline$\widehat{A} 15 m(s)$ & $1.185 \pm 0.378$ & $1.445 \pm 0.520$ & $1.372 \pm 0.489$ & 0.814 & $\mathrm{~F}=5.384 *$ \\
\hline $\mathrm{A} 15 \mathrm{~m}_{\mathrm{D}}(\mathrm{s})$ & $1.212 \pm 0.396$ & $1.494 \pm 0.573$ & $1.437 \pm 0.501$ & 0.689 & $\mathrm{~F}=3.218^{*}$ \\
\hline $\mathrm{S} 20 \mathrm{~m}(\mathrm{~s})$ & $3.002 \pm 0.117$ & $3.052 \pm 0.180$ & $3.194 \pm 0.128$ & 0.967 & $\mathrm{~F}=30.166$ * \\
\hline $\mathrm{S} 20 \mathrm{~m}_{\mathrm{D}}(\mathrm{s})$ & $3.096 \pm 0.154$ & $3.215 \pm 0.292$ & $3.344 \pm 0.162$ & 0.866 & $\mathrm{~F}=7.488 *$ \\
\hline $\mathrm{T}_{\mathrm{TEST}}(\mathrm{s})$ & $10.321 \pm 0.402$ & $10.481 \pm 0.711$ & $11.282 \pm 0.695$ & 0.970 & $\mathrm{~F}=33.330$ * \\
\hline $\mathrm{DM}(\mathrm{s})$ & $18.038 \pm 0.860$ & $18.351 \pm 1.252$ & $19.601 \pm 1.377$ & 0.960 & $\mathrm{~F}=25.079 *$ \\
\hline Slalom (s) & $4.117 \pm 0.178$ & $4.199 \pm 0.253$ & $4.443 \pm 0.213$ & 0.956 & $\mathrm{~F}=22.797 *$ \\
\hline Slalom $_{\mathrm{D}}(\mathrm{s})$ & $4.214 \pm 0.180$ & $4.349 \pm 0.272$ & $4.629 \pm 0.292$ & 0.959 & $\mathrm{~F}=24.441 *$ \\
\hline COD (s) & $11.922 \pm 0.463$ & $12.114 \pm 0.787$ & $12.582 \pm 0.905$ & 0.927 & $\mathrm{~F}=13.773 *$ \\
\hline $\mathrm{COD}_{\mathrm{D}}(\mathrm{s})$ & $12.482 \pm 0.404$ & $12.713 \pm 0.825$ & $13.036 \pm 0.653$ & 0.953 & $\mathrm{~F}=21.394$ * \\
\hline $\operatorname{COND}(\mathrm{s})$ & $12.852 \pm 0.840$ & $13.144 \pm 1.144$ & $13.643 \pm 1.180$ & / & / \\
\hline CMJ (cm) & $41.16 \pm 6.20$ & $39.15 \pm 5.93$ & $35.79 \pm 4.33$ & 0.992 & $\mathrm{~F}=119.140$ * \\
\hline $\mathrm{CMJ}_{\mathrm{AS}}(\mathrm{cm})$ & $48.77 \pm 6.30$ & $47.62 \pm 6.76$ & $43.67 \pm 5.60$ & 0.984 & $\mathrm{~F}=63.837^{*}$ \\
\hline $\mathrm{SJ}(\mathrm{cm})$ & $34.59 \pm 5.77$ & $33.49 \pm 5.70$ & $30.28 \pm 4.69$ & 0.974 & $\mathrm{~F}=38.620 *$ \\
\hline SGJ (cm) & $49.34 \pm 6.61$ & $48.05 \pm 7.66$ & $43.02 \pm 3.72$ & 0.929 & $\mathrm{~F}=14.044$ * \\
\hline
\end{tabular}

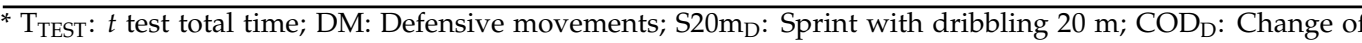
direction with dribbling; Slalom: Slalom; Slalom $\mathrm{D}_{\mathrm{D}}$ S Slalom with dribbling; $\mathrm{A} 15 \mathrm{~m}_{\mathrm{D}}$ : Acceleration with dribbling $15 \mathrm{~m}$; COD: Change of direction; COND: Control of dribbling; S20m: Sprint $20 \mathrm{~m}$; A15m: Acceleration $15 \mathrm{~m}$; Q5m $\mathrm{m}_{\mathrm{D}}$ : Quickness with dribbling $5 \mathrm{~m}$; Q5m: Quickness $5 \mathrm{~m}$; CMJ: Countermovement jump without arm swing; SJ: Squat jump; $\mathrm{CMJ}_{\mathrm{AS}}$ : Countermovement jump with arm swing; SGJ: Sargent jump; ${ }^{*} p$ values: $p=0.000$

The KMO showed a high statistical significance of multivariate adequacy of the given variables at the level of $0.561\left(\chi^{2}=848\right.$. 338, $\left.p<0.001\right)$ for guards, at the level of 0.677 $\left(\chi^{2}=689.135, p=0.001\right)$ for forwards, and at the level of $0.558\left(\chi^{2}=744.770, p=0.001\right)$. For all playing positions, the factor analysis extracted three significant factors (Table 2), which cumulatively explained $76.867,88.123$ and $87.633 \%$ of variance in guards, forwards, and centers, respectively.

Table 2. Saturated factors with the structure indicators of the explained variance.

\begin{tabular}{cccccccccc}
\hline \multirow{2}{*}{ Factor } & \multicolumn{9}{c}{ Extraction Sums of Squared Loadings } \\
\cline { 2 - 10 } & \multicolumn{3}{c}{ Total } & \multicolumn{3}{c}{$\%$ of Variance } \\
\hline & Guard & Forward & Center & Guard & Forward & Center & Guard & Forward & Center \\
1 & 6.719 & 9.997 & 11.333 & 39.523 & 58.804 & 66.664 & 39.523 & 58.804 & 66.664 \\
2 & 3.644 & 3.899 & 2.465 & 21.435 & 22.936 & 14.499 & 60.958 & 81.739 & 81.162 \\
3 & 2.705 & 1.085 & 1.100 & 15.909 & 6.384 & 6.471 & 76.867 & 88.123 & 87.633 \\
\hline
\end{tabular}


Table 3 shows the structure matrix with the variable saturation for each playing position. Measured physical characteristics provide a similar factor structure for each position, with a lateral change of direction speed being highly ranked in guards, jumping ability in forwards, and change of direction speed between baseline and free-throw line in centers. The second factor included straight-run speed measures with and without the ball for all three positions. The third factor included a jumping performance in guards, change of direction speed while dribbling the ball, defensive movement in forwards, and jumping performance in centers (with emphasis on jumps with arm swings). This suggests that the measured characteristics with regard to different playing positions have different structures in the function of isolated factors, which may be attributed to their adaptation to specific training process.

Table 3. Factor analysis structure matrix for each playing position.

\begin{tabular}{|c|c|c|c|c|c|c|}
\hline \multirow{2}{*}{ Factor } & \multicolumn{2}{|c|}{ Guard } & \multicolumn{2}{|c|}{ Forward } & \multicolumn{2}{|c|}{ Center } \\
\hline & Variables & Value & Variables & Value & Variables & Value \\
\hline \multirow{9}{*}{ 1st factor } & $\mathrm{T}_{\text {TEST }}$ & 0.804 & $\mathrm{CMJ}_{\mathrm{AS}}$ & -0.966 & COND & 0.962 \\
\hline & $\mathrm{DM}$ & 0.783 & CMJ & -0.957 & $\mathrm{COD}_{\mathrm{D}}$ & 0.940 \\
\hline & $\mathrm{s} 20 \mathrm{~m}_{\mathrm{D}}$ & 0.762 & S20 & 0.934 & COD & 0.916 \\
\hline & Slalom & 0.759 & $\mathrm{~T}_{\mathrm{TEST}}$ & 0.918 & Slalom & 0.891 \\
\hline & Slalom $_{\mathrm{D}}$ & 0.754 & SJ & -0.912 & $\mathrm{~T}_{\mathrm{TEST}}$ & 0.887 \\
\hline & COD & 0.749 & SGJ & -0.897 & Slalom $_{\mathrm{D}}$ & 0.848 \\
\hline & $\mathrm{COD}_{\mathrm{D}}$ & 0.749 & Slalom & 0.878 & $\mathrm{DM}$ & 0.834 \\
\hline & COND & 0.720 & Slalom $_{\mathrm{D}}$ & 0.834 & $\mathrm{~S} 20 \mathrm{~m}$ & 0.821 \\
\hline & S20m & 0.624 & $\mathrm{COD}_{\mathrm{D}}$ & 0.823 & $\mathrm{~S} 20 \mathrm{~m}_{\mathrm{D}}$ & 0.818 \\
\hline \multirow{4}{*}{ 2nd factor } & $\mathrm{A} 15 \mathrm{~m}$ & -0.984 & $\mathrm{~A} 15 \mathrm{~m}$ & -0.983 & $\mathrm{~A} 15 \mathrm{~m}$ & 0.993 \\
\hline & $\mathrm{Q} 5 \mathrm{~m}_{\mathrm{D}}$ & 0.984 & $\mathrm{~A} 15 \mathrm{~m}_{\mathrm{D}}$ & -0.977 & $\mathrm{~A} 15 \mathrm{~m}_{\mathrm{D}}$ & 0.990 \\
\hline & Q5m & 0.980 & Q5m & 0.967 & Q5m & -0.980 \\
\hline & $\mathrm{A} 15 \mathrm{~m}_{\mathrm{D}}$ & -0.973 & $\widehat{Q} 5 m_{D}$ & 0.959 & $\widehat{Q} 5 m_{D}$ & -0.969 \\
\hline \multirow{4}{*}{ 3rd factor } & CMJ & 0.974 & COND & 0.869 & SGJ & 0.949 \\
\hline & $\mathrm{CMJ}_{\mathrm{AS}}$ & 0.944 & DM & 0.846 & $\mathrm{CMJ}_{\mathrm{AS}}$ & 0.943 \\
\hline & SJ & 0.886 & COD & 0.828 & CMJ & 0.871 \\
\hline & SGJ & 0.813 & $\mathrm{~S} 20 \mathrm{~m}_{\mathrm{D}}$ & 0.827 & SJ & 0.860 \\
\hline
\end{tabular}

TEST: $t$-test total time; DM: Defensive movements; S20m $\mathrm{m}_{\mathrm{D}}$ : Sprint with dribbling $20 \mathrm{~m}$; $\mathrm{COD}_{\mathrm{D}}$ : Change of

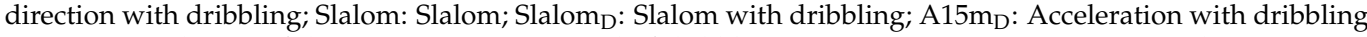
15 m; COD: Change of direction; COND: Control of dribbling; S20m: Sprint 20 m; A15m: Acceleration 15 m; Q5m $\mathrm{D}$ : Quickness with dribbling $5 \mathrm{~m}$; Q5m: Quickness $5 \mathrm{~m}$; CMJ: Countermovement jump without arm swing; SJ: Squat jump; $\mathrm{CMJ}_{\mathrm{AS}}$ : Countermovement jump with arm swing; SGJ: Sargent jump.

The results of the defined regression analysis have shown high predictive potential for PP $\mathrm{INDEX}_{\text {of guards }}\left(\mathrm{AdjR}^{2}=0.893, \mathrm{~F}=165.597, p<0.001\right.$, Standard Error of the Estimate $=0.33)$, forwards $\left(\mathrm{Adj}^{2}=0.896, \mathrm{~F}=170.577, p<0.001\right.$, Standard Error of the Estimate $=0.31)$, and centers $\left(\mathrm{AdjR}^{2}=0.875, \mathrm{~F}=138.412, p<0.001\right.$, Standard Error of the Estimate $=0.34$ ). The final mathematical models for evaluation of PPINDEX of guards, forwards, and centers is as follows:

$\mathrm{PP}_{\text {INDEX }}$ of guards $=-6.860+(0.932 \times T$ test $)-(1.656 \times$ Acceleration $15 \mathrm{~m})-(0.020$ $\times$ Countermovement jump),

$\mathrm{PP}_{\text {INDEX }}$ of forwards $=-3.436-(0.046 \times$ Countermovement jump with arm swing $)$ $-(1.295 \times$ Acceleration $15 \mathrm{~m})+(0.582 \times$ Control of dribbling $)$,

$\mathrm{PP}_{\text {INDEX }}$ of centers $=-4.126+(0.604 \times$ Control of dribbling $)-(1.315 \times$ Acceleration $15 \mathrm{~m})-(0.037 \times$ Sargent jump $)$.

In this manner, by a very simple mathematical model, coaches could be provided with a tool for the evaluation of players' physical preparedness according to position, in terms of a deterministic, fully controlled system.

The regression analysis further reduced the multidimensionality of players' physical preparedness to the most essential components that predict the PP INDEX of young players with high precision. The best predictors in guards included $\mathrm{T}_{\mathrm{TEST}}, \mathrm{A} 15 \mathrm{~m}, \mathrm{CMJ}$. The best 
predictors in forwards were $\mathrm{CMJ}_{\mathrm{AS}}, \mathrm{A} 15 \mathrm{~m}, \mathrm{COND}$. The best predictors in centers were COND, A15m, and SGJ. Thus, the highest-ranked variables in each factor were the best predictors of $\mathrm{PP}_{\mathrm{INDEX}}$ for the corresponding positions. The regression model allows for the qualitative and quantitative evaluation of players on the three investigated positions (See Figure 3).

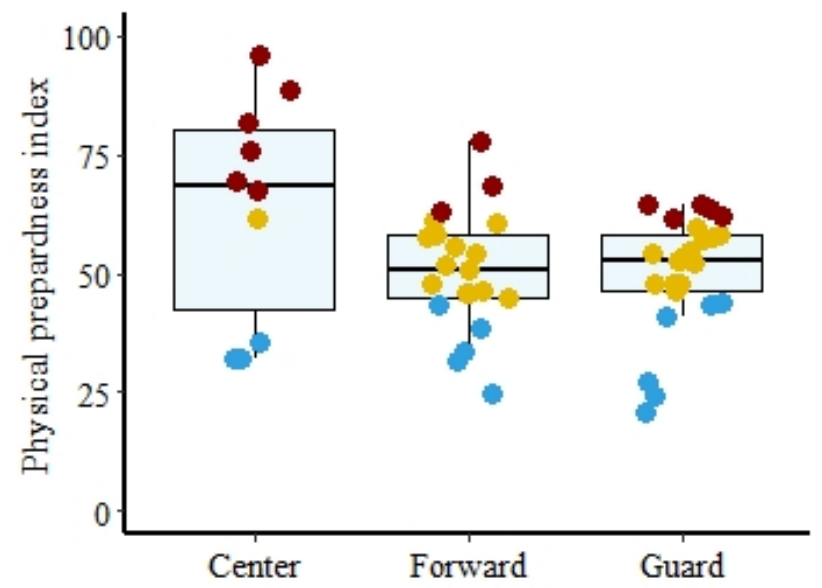

Physical prepardness level

- High

- Low

- Moderate

Figure 3. Positioning of players according to playing position from the aspect of specific preparation level.

\section{Discussion}

This study investigated the hierarchical structure of physical characteristics in elite young basketball players and evaluated their predictive value in the evaluation of players' physical preparedness. The main findings showed that specific change of direction speed performance was the highest-ranked characteristic in guards, specific jumping performance was the highest-ranked characteristic in forwards, while the control of specific movements while dribbling the ball was the highest-ranked characteristic in centers. Moreover, a significant prediction model for the evaluation of physical preparedness was defined for each playing position. These findings are of high importance as they provide a screening tool for selection and training evaluation processes.

Considering the structure of the basketball game, players are required to perform numerous technical-tactical elements characterized by agile movements in space in a planned manner or as a response to the opponent's actions [21]. Shooting guards within their roles and duties perform a higher number of lateral shuffles, forward and backward sprints on relatively bigger area than centers or small forwards. This could be attributed to the role in the game that guards have, such as losing the defender further from the basket by quick directional changes with and without the ball and quick return to defend the basket. Therefore, running speed, agility, and rapid recovery are critical fitness components, particularly for this position [9,13-15].

Forwards, on the other hand, typically perform a high number of jumps whether offensively to score the basket or defensively when rebounding, which is also emphasized in the training process. Thereby, jumping characteristics are of high importance for this position. Basketball players typically perform 40-50 jumps per game, generating force rapidly to perform various tasks such as rebounding, blocking opponent shot attempts, and creating elevation for a jump shot [2]. The movement structure of CMJ and $\mathrm{CMJ}_{\mathrm{AS}}$ corresponds to the bilateral vertical jumps that players most often perform when they are shooting from the distance to advance their ball release height and when they are trying to block the opponent. In addition, forwards are also responsible for the quick return to defence and to defend the space by quick lateral shuffles.

Centers are usually referred to as "frontcourt", often acting as their team's primary below-the-basket rebounders and shot blockers. They also receive passes to take inside shots for which they must control their body, opponent, and the ball. Therefore, it is not 
surprising that centers, as major players on the team, require a high level of control of the specific movement with the ball to maintain their body position when battling with the opponents for important positions under the basket. However, considering the game rules that do not allow staying below the basket longer than $5 \mathrm{~s}$, center is required to move constantly in a square-shaped space from the baseline to the free-throw line. They need to be agile compared to other centers so they could position themselves in a good position repeatedly.

The second factor consisting of acceleration and sprint for all positions indicated the importance of these characteristics for basketball players. Short sprints represent a multidimensional movement skill that requires an explosive concentric and SSC force production of a number of lower-limb muscles [22]. During a game, the players are rarely in a situation where they have to sprint across the whole court. Therefore, sprint tests over shorter distances and acceleration are more appropriate to administer to basketball players [3,8,22]. Indeed, to a large degree (certainly more than power and agility) speed is genetically predetermined, thereby fast players are selected rather than "made fast", especially considering the sample of this study that consisted of elite players for their age category [23]. This does not reduce the importance of this factor, but additionally suggests that the applied strength and conditioning training could include strength and power exercises that may additionally improve running speed and acceleration or reduce the risk of injury caused by these activities [24-26]. It is interesting to mention that center were slightly faster than forwards in the A15 and A15 tests (Table 1). However, if an index of technical efficiency is calculated (the ratio between the A15 and A15 tests), it may be concluded that forwards are still more efficient than centers. Although there are no data in the available literature on the $15 \mathrm{~m}$ acceleration test in basketball, results of some previous research showed no significant difference between playing position in the $20 \mathrm{~m}$ sprint $[9,13]$. Even more, these authors suggested that despite their size and weight, centers are as fast as smaller players. Besides that, significant effect of playing position on sprint performance increase in shorter (10 $\mathrm{m}$ and shorter) and longer (20 $\mathrm{m}$ and longer) distance $[13,14]$ which strongly support our findings.

The last factor is vertical jump performances in guards and centers, showing that these characteristics, although not dominant, are a very important pillar of a basketball player's physical preparedness. The most representative variable in the third factor was the countermovement jump for guards and Sargent jump for centers. The obtained differences in hierarchy of this factor correspond to differences in how guards and centers perform jumps in the game. Guards are typically jumping free from the opposing player (i.e., no contact with opposing player) and from previously performed movement, while centers are typically jumping from the spot, while in contact with the opposing player with one hand and reaching high with the other to block, rebound or score. Unlike guards and centers, the third factor extracted change of direction speed and speed variables, whereby most representatives were the control of dribbling. This is not surprising, given that forwards often perform dribble penetration to advance to the basket [9,13-15].

There is a scarcity of studies that address the specific characteristics of physical fitness in basketball players, even though the battery of basic performance tests are widely used. The reason for that could lie in a fact that possibility of providing a sample of the best selected players for the age category is low. Research dealing with the hierarchical structure and equation of specification in relation to specific performance tests in basketball is practically non-existent in the available literature. The lack of reference to these problems has certainly reduced the possibility to compare our findings with other studies. Data on the defined latent structure of standard indicators of situational efficiency in the game of basketball [27] or in relation to the tests of generic nature [28] can be found in the available literature. The results of that research have shown that the highest total variance in 13 male and 13 female semiprofessional basketball players was represented by aerobic capacity and in-game physical conditioning [28]. In addition, as one of the main limitations of this study, the authors mentioned the need for the inclusion of specific basketball-field tests (e.g., 
agility with and without the ball, anaerobic capacity) to evaluate the physical performance of basketball players [28]. In relation to the research that used similar methodology [20], the results suggest that it is possible to create sport- position-specific prediction model for evaluation physical preparedness.

\section{Limitations}

However, some limitations should be acknowledged when interpreting the results of this research. An apparent limitation of this study is the results may not be generalized to other age groups or females. In order to apply the obtained results in general, it is necessary to conduct extensive research that includes the examination of physical ability on a large sample of basketball players, of different ages, competitive level and for both genders. Another limitation originates from the cross-sectional design that does not allow for the identification of the effects of physical activity from the initial selection of the subjects.

\section{Conclusions}

The results obtained in this research show that the measured characteristics with regard to different playing positions have different structures in the function of isolated factors under the influence of different mechanisms with regard to the training process. As a factor analysis has a primarily discriminatory character, the first factor with observed variables where the basketball players differ most is the most important one. Specific change direction agility abilities, i.e., specific locomotion on the court is the most important element within guard position in elite youth basketball players. Specific jumping ability is the most important element within the forward position. Control of specific movement with the ball is the most important element within center position.

\section{Practical Applications}

With the multiple regression analysis, the influence of the selected variables on the physical performance index ( $\left.\mathrm{PP}_{\mathrm{INDEX}}\right)$ was obtained, and the equation of specific basketball preparedness according to playing position. This index represents the position of the participant on a hypothetical scale with a minimum of 0 and a maximum of 100 points. In this manner, it is possible to obtain relevant data in relation to physical ability characteristics and, indirectly, to obtain the performance potential of a given athlete. Thus, a useful means for the level of physical fitness determination of youth basketball players has been obtained, as well as a comprehensive reference model for use in selection procedures, screening candidates, or to monitor the efficacy of training regimes.

Author Contributions: Conceptualization, J.I. and M.D.; methodology, J.I., M.D. and S.J.; validation, F.K. and G.G.; formal analysis, J.I., M.D. and F.K.; investigation, J.I. and S.J.; resources, J.I., G.G., F.K. and S.J.; data curation, J.I., G.G., F.K. and N.K.; writing-original draft preparation, J.I., M.D., G.G. and F.K.; writing-review and editing, J.I., F.K., G.G. and N.K.; supervision, M.D., F.K. and G.G.; project administration, J.I. and F.K. All authors have read and agreed to the published version of the manuscript.

Funding: This research received no external funding.

Institutional Review Board Statement: The study was conducted according to the guidelines of the Declaration of Helsinki and approved by the Ethics Commission of the Faculty of Sport and Physical Education, University of Belgrade (protocol code 482-2, February 2011).

Informed Consent Statement: Informed consent was obtained from all subjects involved in the study.

Data Availability Statement: The data presented in this study are available on request from the corresponding author.

Acknowledgments: The paper was realized as part of project III47015 sponsored by Ministry of Science and Technological Development in the Republic of Serbia.

Conflicts of Interest: The authors declare no conflict of interest. 


\section{References}

1. Mancha-Triguero, D.; García-Rubio, J.; Calleja-González, J.; Ibáñez, S.J. Physical fitness in basketball players: A systematic review. J. Sports Med. Phys. Fit. 2019, 59, 1513-1525. [CrossRef]

2. Wen, N.; Dalbo, V.J.; Burgos, B.; Pyne, D.B.; Scanlan, A.T. Power testing in basketball: Current practice and future recommendations. J. Strength Cond. Res. 2018, 32, 2686-2700. [CrossRef]

3. Zarić, I.; Dopsaj, M.; Marković, M. Match performance in young female basketball players: Relationship with laboratory and field tests. Int. J. Perform. Anal. Sport 2018, 18, 90-103. [CrossRef]

4. Stojanović, E.; Stojiljković, N.; Scanlan, A.T.; Dalbo, V.J.; Berkelmans, D.M.; Milanović, Z. The activity demands and physiological responses encountered during basketball match-play: A systematic review. Sports Med. 2018, 48, 111-135. [CrossRef] [PubMed]

5. Ferioli, D.; Rampinini, E.; Bosio, A.; La Torre, A.; Azzolini, M.; Coutts, A.J. The physical profile of adult male basketball players: Differences between competitive levels and playing positions. J. Sports Sci. 2018, 36, 2567-2574. [CrossRef] [PubMed]

6. Belyakova, A.; Gorskaya, I. Psychomotor abilities as a factor of future success in athletes. Hum. Sports Med. 2021, 21, 102-107. [CrossRef]

7. Zatsiorsky, V.M.; Kraemer, W.J. Science and Practice of Strength Training, 2nd ed.; Human Kinetics: Champaign, IL, USA, 2006.

8. Ivanović, J.; Dopsaj, M.; Jakovljević, S.; Karalejić, M. Relationship between isometric neuromuscular function of the leg extensors with performance tests in basketball. Russ. Open Med. J. 2019, 8, 1-8. [CrossRef]

9. Drinkwater, E.J.; Pyne, D.B.; McKenna, M.J. Design and interpretation of anthropometric and fitness testing of basketball players. Sports Med. 2008, 38, 565-578. [CrossRef] [PubMed]

10. Toselli, S.; Campa, F.; Maietta Latessa, P.; Greco, G.; Loi, A.; Grigoletto, A.; Zaccagni, L. Differences in Maturity and Anthropometric and Morphological Characteristics among Young Male Basketball and Soccer Players and Non-Players. Int. J. Environ. Res. Public Health 2021, 18, 3902. [CrossRef]

11. Towlson, C.; Cobley, S.; Parkin, G.; Lovell, R. When does the influence of maturation on anthropometric and physical fitness characteristics increase and subside? Scand. J. Med. Sci. Sports 2018, 28, 1946-1955. [CrossRef] [PubMed]

12. Arede, J.; Fernandes, J.; Moran, J.; Norris, J.; Leite, N. Maturity timing and performance in a youth national basketball team: Do early-maturing players dominate? Int. J. Sports Sci. Coach 2021, 16, 722-730. [CrossRef]

13. Delextrat, A.; Cohen, D. Strength, power, speed, and agility of women basketball players according to playing position. J. Strength Cond. Res. 2009, 23, 1974-1981. [CrossRef]

14. Köklü, Y.; Alemdaroğlu, U.; Koçak, F.; Erol, A.; Findikoğlu, G. Comparison of Chosen Physical Fitness Characteristics of Turkish Professional Basketball Players by Division and Playing Position. J. Hum. Kinet. 2011, 30, 99-106. [CrossRef]

15. Boone, J.; Bourgois, J. Morphological and Physiological Profile of Elite Basketball Players in Belgium. Int. J. Sports Physiol. Peform. 2013, 8, 630-638. [CrossRef] [PubMed]

16. Brini, S.; Ben Abderrahman, A.; Boullosa, D.; Hackney, A.C.; Zagatto, A.M.; Castagna, C.; Bouassida, A.; Granacher, U.; Zouhal, H. Effects of a 12-Week Change-of-Direction Sprints Training Program on Selected Physical and Physiological Parameters in Professional Basketball Male Players. Int. J. Environ. Res. Public Health 2020, 17, 8214. [CrossRef]

17. Markovic, G.; Dizdar, D.; Jukic, I.; Cardinale, M. Reliability and factorial validity of squat and countermovement jump tests. J. Strength Cond. Res. 2004, 18, 551-555. [CrossRef]

18. Maggioni, M.A.; Bonato, M.; Stahn, A.; La Torre, A.; Agnello, L.; Vernillo, G.; Castagna, C.; Merati, G. Effects of Ball Drills and Repeated-Sprint-Ability Training in Basketball Players. Int. J. Sports Physiol. Perform. 2019, 14, 757-764. [CrossRef]

19. Rojas-Valverde, D.; Pino-Ortega, J.; Gómez-Carmona, C.D.; Rico-González, M. A Systematic Review of Methods and Criteria Standard Proposal for the Use of Principal Component Analysis in Team's Sports Science. Int. J. Environ. Res. Public Health 2020, 17, 8712. [CrossRef]

20. Majstorović, N.; Dopsaj, M.; Grbić, V.; Savić, Z.; Vićentijević, A.; Aničić, Z.; Zadražnik, M.; Toskić, L.; Nešić, G. Isometric Strength in Volleyball Players of Different Age: A Multidimensional Model. Appl. Sci. 2020, 10, 4107. [CrossRef]

21. Abdelkrim, N.B.; Chaouachi, A.; Chamari, K.; Chtara, M.; Castagna, C. Positional role and competitive-level differences in elite-level men's basketball players. J. Strength Cond. Res. 2010, 24, 1346-1355. [CrossRef] [PubMed]

22. Markovic, G.; Mikulic, P. Neuro-Musculoskeletal and Performance Adaptations to Lower Extremity Plyometric Training. Sports Med. 2010, 4, 859-895. [CrossRef]

23. Ben-Zaken, S.; Eliakim, A.; Nemet, D.; Meckel, Y. Genetic Variability Among Power Athletes: The Stronger vs. the Faster. J. Strength Cond. Res. 2019, 33, 1505-1511. [CrossRef] [PubMed]

24. Young, W.B. Transfer of strength and power training to sports performance. Int. J. Sports Physiol. Perform. 2006, 1, 74-83. [CrossRef] [PubMed]

25. Zouita, S.; Zouita, A.B.M.; Kebsi, W.; Dupont, G.; Ben Abderrahman, A.; Ben Salah, F.Z.; Zouhal, H. Strength training reduces injury rate in elite young soccer players during one season. J. Strength Cond. Res. 2016, 30, 1295-1307. [CrossRef]

26. Case, M.J.; Knudson, D.V.; Downey, D.L. Barbell squat relative strength as an identifier for lower extremity injury in collegiate athletes. J. Strength Cond. Res. 2020, 34, 1249-1253. [CrossRef] [PubMed]

27. Sporiš, G.; Šango, J.; Vučetić, V.; Mašina, T. The latent structure of standard game efficiency indicators in basketball. Int. J. Perform. Anal. Sport 2006, 6, 120-129. [CrossRef]

28. Gómez-Carmona, C.D.; Mancha-Triguero, D.; Pino-Ortega, J.; Ibáñez, S.J. Exploring Physical Fitness Profile of Male and Female Semiprofessional Basketball Players through Principal Component Analysis-A Case Study. J. Funct. Morphol. Kinesiol. $2021,6,67$. [CrossRef] [PubMed] 